\title{
Effect of Additives on Swelling of Covalent DNA Gels ${ }^{\dagger}$
}

\author{
Diana Costa,*,»\$ M. Graça Miguel, $\$$ and Björn Lindman $\$$, \\ Physical Chemistry 1, Centre for Chemistry and Chemical Engineering, Lund University, Box 124, S-22100 \\ Lund, Sweden, and Department of Chemistry, University of Coimbra, Coimbra, Portugal
}

Received: November 29, 2006; In Final Form: March 6, 2007

\begin{abstract}
The volumetric response of polymer gels on cosolute addition depends on the interaction of the polymer with the cosolute and can be used as a simple and sensitive way of elucidating these interactions. Here we report on DNA networks, prepared by crosslinking double-stranded DNA with ethylene glycol diglycidyl ether (EGDE); these have been investigated with respect to their swelling in aqueous solution containing different additives, such as metal ions, polyamines, charged proteins, and surfactants. The deswelling on addition of metal ions occurs at lower concentrations with increasing valency of the counterion. The collapse of the gels in the presence of trivalent ions seems to follow the same kind of mechanism as the interaction in solution, but addition of these ions leads to DNA denaturation and formation of single-stranded DNA. Striking features were found in the deswelling of DNA gels by chitosan, spermine, spermidine, lysozyme, poly-L-lysine and poly-L-arginine. Chitosan is the most efficient cosolute of those investigated with respect to DNA gel collapse. The effect of the cationic surfactant tail length on the volume phase transition of DNA gels was studied as a function of surfactant concentration. Cationic surfactants effectively collapsed the gel from the critical aggregation concentration (cac), decreasing with increasing length of the hydrophobic tail. In several cases, the deswelling as a function of cosolute concentration shows a pronounced two-step behavior, which is interpreted in terms of a combination of DNA chain condensation and general osmotic deswelling. The studies included investigations on the state of the DNA chain after deswelling, on the reversibility of the deswelling as well as on the kinetics. With the exception for the trivalent lanthanide ions, it appears that the DNA chain always retains a double-helix conformation; with these metal ions, single-stranded DNA is found. The deswelling appears to be reversible as exemplified by addition of anionic surfactant subsequent to gel collapsed by cationic surfactant and addition of sodium bromide to gels collapsed by a polycation. An investigation of the kinetics shows that an increase in the surfactant tail length gives a pronouncedly slower deswelling kinetics.
\end{abstract}

\section{Introduction}

Polymer gels that respond to changes in the surrounding environment with a volume transition, often referred as responsive gels, have attracted much interest in the past few years. ${ }^{1-8}$ In this group are the polyelectrolyte gels, which consist of charged polymer networks, counterions, and solvent and are usually synthesized by chemically cross-linking charged or titrating polymers. The environmental conditions include changes in different parameters such as $\mathrm{pH},{ }^{6,9-11}$ solvent composition, ${ }^{12}$ ionic strength, ${ }^{13}$ temperature, ${ }^{14,15}$ pressure, ${ }^{16}$ buffer composition, ${ }^{17}$ chemicals, ${ }^{18}$ surfactants, ${ }^{19-28}$ and photoelectric stimuli. ${ }^{29}$ Because of their significant swelling and syneresis in response to external stimuli, these polymeric networks are used for a variety of applications such as contact lenses, ${ }^{30}$ diapers, wround dressing, membrane materials, pharmaceutical products, ${ }^{31}$ monolithic drug delivery systems, ${ }^{32}$ chromatography packing materials, and agriculture. ${ }^{33}$ Moreover, cross-linked gels have been investigated for many biomedical uses, including tissue culture, ${ }^{34}$ enzyme activity controlling systems, ${ }^{35}$ and materials for improved biocompatibility, ${ }^{36}$ in the design and analysis of artificial

$\dagger$ Part of the special issue "International Symposium on Polyelectrolytes (2006)".

* Corresponding author. Address: Departamento de Química, Universidade de Coimbra, 3004-535 Coimbra, Portugal. Fax: +351- 239827703. E-mail: diana.costa@fkem1.lu.se.

$\doteqdot$ Lund University.

$\S$ University of Coimbra. muscles and biosensors and in the design of intelligent controlled drug release devices for site-specific drug delivery. The scientific interest is due to the complex interplay of counteracting forces, which are of equal order of magnitude and which determine the swelling of the gels. ${ }^{36}$ The main contributions are the osmotic pressure originating from the electrostatically confined small ions inside the gel, ${ }^{37}$ the effective electrostatic interactions between the charged groups ${ }^{38-41}$ and hydrophobic interactions. Factors such as the nature of the polymer, the polymer-solvent compatibility, the degree of cross-linking, the nature of the buffer composition, and the nature of the counterion as well play an important role in determining the swelling behavior. ${ }^{42-44}$

Complexes of polyelectrolyte gels with oppositely charged surfactants were intensively studied in the past decade ${ }^{19-28}$ due to their interesting practical applications. Phase coexistence has been observed during volume transitions of polyelectrolyte gels following the uptake of surfactant ions from the solution. ${ }^{45-47}$ Here the transition to the collapsed state is promoted by the favorable electrostatic interaction between the polyion and surfactant micelles. No important differences between the ordered micelle structures formed with cross-linked and linear polyions have been reported so far. However, the structure and stability of the phases have important consequences for swelling and volume transition dynamics in gels.

Surfactants are not the only class of molecules interacting strongly with DNA. For instance, the binding of charged proteins, as well as poly-L-lysine and poly-L-arginine, multi- 
valent ions, and multivalent polyamines, such as spermidine or spermine, are known to condense large DNA coils, ${ }^{48-51}$ resulting in (associative) phase separation in sufficiently concentrated solutions.

DNA compaction in living cells is a process of extraordinary biological importance. The compaction of DNA in vivo is achieved by histone proteins. ${ }^{52}$ The condensation of DNA in vitro can be induced by a number of small polyvalent ions ${ }^{53,54}$ and by lowering the dielectric constant. ${ }^{55}$ Electrostatic interactions have important effects on the physical properties of macromolecules such as DNA, and electrostatic ion-ion correlations, which go beyond traditional mean-field theory, can explain the phenomenon known as DNA condensation. It has been shown that the easiest way to achieve an effectively attractive interaction between equally charged aggregates, through a strong coupling, is by using multivalent counterions. The observed attraction is thought to contribute to the condensation and aggregation of DNA and other highly charged polymers. ${ }^{56}$

One of the major goals of the present time is the treatment of diseases through gene therapy. There are several promising studies on nonviral gene delivery systems, including "naked" DNA and DNA condensed with agents such as cationic lipids, polymers, and polycations. ${ }^{57-63}$ The DNA network-additive complex may constitute a possibility for many uses in medicine as drug delivery systems, and drug control during administration.

In the present paper, we report on the swelling behavior of covalently cross-linked DNA on addition of different cosolutes, which include inorganic salts with different cation valency, polyamines such as spermine and spermidine, cationic macromolecules such as poly-L-lysine, poly-L-arginine, lysozyme and chitosan, and different classes of surfactants. We demonstrate that simple gel experiments are quite useful to study not only DNA-surfactant interactions, but also interactions between DNA and cationic species interactions, in general. We found that DNA gels are very interesting as "responsive" systems, since drastic volume changes can be induced by changes, often very small, in the composition of the swelling medium. The swelling of the gels appears to be reversible, as exemplified by the deswelling/swelling process induced by consecutive addition of cationic and anionic surfactant, or chitosan and $\mathrm{NaCl}$. The contraction of DNA gels in certain cases displays a two-step behavior not observed for other polyelectrolyte gels; this is attributed to an initial compaction of DNA.

\section{Materials and Methods}

Materials. Deoxyribonucleic acid (DNA) (from salmon testes, sodium salt; $\sim 2000$ base pairs), $N, N, N^{\prime}, N^{\prime}$-tetramethylethylenediamine (TEMED), sodium hydroxide $(\mathrm{NaOH})$, and sodium bromide $(\mathrm{NaBr})$, all from Sigma, and ethylene glycol diglycidyl ether (EGDE) from Aldrich were used as supplied. Sodium, lithium, potassium, rubidium, cesium, calcium, magnesium, and strontium clorides $(\mathrm{NaCl}, \mathrm{LiCl}, \mathrm{KCl}, \mathrm{RbCl}, \mathrm{CsCl}$, $\mathrm{CaCl}_{2}, \mathrm{MgCl}_{2}$, and $\mathrm{SrCl}_{2}$, respectively) were purchased from Sigma. Cationic alkyltrimethylammonium bromide surfactants $\left(\mathrm{C}_{n} \mathrm{TAB}\right)$ and sodium dodecyl sulfate (SDS) were obtained from Serva and used without further purification. Spermine tetrahydrochloride, spermidine trihydrochloride, poly-L-lysine (PL, weight $\left.M_{\mathrm{w}}=5 \mathrm{kDa}\right)$, and poly-L-arginine $\left(\mathrm{PA}, M_{\mathrm{w}}=5 \mathrm{kDa}\right)$ from Sigma were utilized without further purification. Stock solutions of spermine and spermidine in deionized water were prepared from chloride salts of the polyamines and were adjusted to $\mathrm{pH} 6.5 \pm 0.2$ with $\mathrm{HCl}$ or $\mathrm{NaOH}$. Stock solutions of polyL-lysine (PL) and poly-L-arginine (PA) were prepared using 10
$\mathrm{mM}$ phosphate buffer, $\mathrm{pH}$ 7.4. Lysozyme (95\%) from chicken egg white, three times recrystallized, dialyzed, and lyophilized, and chitosan from crab shells obtained by alkaline deacetylation from chitin were obtained from Sigma ( $85 \%$ deacetylation, $M_{\mathrm{w}}$ $=22 \mathrm{kDa}$ ). As lysozyme is very stable and to a large extent self-buffering, no buffer solution was used. Without any buffer the $\mathrm{pH}$ of the solution is 6.5 and since its isoelectric point is at $\mathrm{pH} 11$, the protein has a positive net charge of eight at this $\mathrm{pH}$. Chitosan stock solution was prepared by dissolving it in sterile $25 \mathrm{mM}$ acetate buffer, $\mathrm{pH}$ 6.0, and then diluted to the final desired concentration. In the case of polyamines and polycations, gel swelling measurements were carried out at $\mathrm{pH}$ 6.5, and concentrations are presented per charge. Millipore filtered water was used in all experiments.

Preparation of Gels. Double-stranded DNA, from salmon testes, was dissolved in water containing $3.7 \mathrm{mM} \mathrm{NaBr}$, to a DNA concentration of 9 wt \%. DNA was chemically crosslinked by using ethylene glycol diglycidyl ether (EGDE) at $\mathrm{pH}$ 9. After adding $1 \mathrm{M} \mathrm{NaOH}$ and TEMED the sample was mixed and then transferred to test tubes and incubated for $2 \mathrm{~h}$ in a water bath at $50{ }^{\circ} \mathrm{C}$. Freshly synthesized gels were neutralized and rinsed with large amounts of $1 \mathrm{mM} \mathrm{NaOH}$ solution. The DNA gels swelled considerably in the $\mathrm{NaOH}$ solution, and due to this fact, the DNA concentration in the gels is lowered. The concentration of DNA in the gels equilibrated with $1 \mathrm{mM} \mathrm{NaOH}$ (reference state) was obtained by weighing gels before and after freeze-drying. A decrease in the DNA concentration from $9 \mathrm{wt}$ $\%$, at preparation time, to $1 \mathrm{wt} \%$, after immersion of the gels in the $\mathrm{NaOH}$ solution, was observed. Thus, the reference state of the experiments is the equilibrium swelling in $1 \mathrm{mM} \mathrm{NaOH}$ solution.

Swelling Experiments. In the swelling experiments, 4-6 gel pieces were immersed in vials containing $8 \mathrm{~mL}$ of aqueous solutions of additive. Owing to the much larger volume of the swelling medium (a factor of more than 100) compared to the volume of the gels, the fraction of surfactant and the other additives bound to the gels was negligible. The equilibrium concentration of additive in the swelling medium was, therefore, equal to the initial concentration. All samples were equilibrated in sealed containers for one week at $25^{\circ} \mathrm{C}$ and shaken slowly during that time, to reach the equilibrium degree of swelling. The swelling ratios are given as $V / V_{0}=\left(D / D_{0}\right){ }^{3}$ where $V$ is the volume and $D$ is the diameter of the gel, where the subscript 0 denotes the corresponding value at the preparation time $\left(D_{0}\right.$ $=$ ca. $1.4 \mathrm{~mm}$ ). The diameters of the gels were measured with a video camera calibrated at a $0.1 \mathrm{~mm}$ scale with the help of an image computer program. ${ }^{64}$ Each data point represents the average of ca. five measurements of $\mathrm{D}$, with a variation of ca. $5 \%$. In the kinetic experiments, a gel cylinder piece was initially equilibrated in $1 \mathrm{mM} \mathrm{NaOH}$. This initial solution was then removed using a Pasteur pipet. When $8 \mathrm{~mL}$ of another surfactant solution was added to the vial, a stopwatch was started. Images were then captured automatically at constant time intervals using the movie function in the computer program. ${ }^{64}$ Due to this procedure, all equilibration experiments were made without stirring. In the measurements of the equilibrium swelling, we observe a certain variation in gel swelling among different gel pieces. With this type of experiment, as a limitation, we have the fact that not all the gel pieces are in the same position in the (optically imperfect) glass vials. However, by studying the volume change of a selected gel piece with time, it is possible to confirm volume changes that, in the normal equilibrium swelling measurement, would fall within the experimental error. 


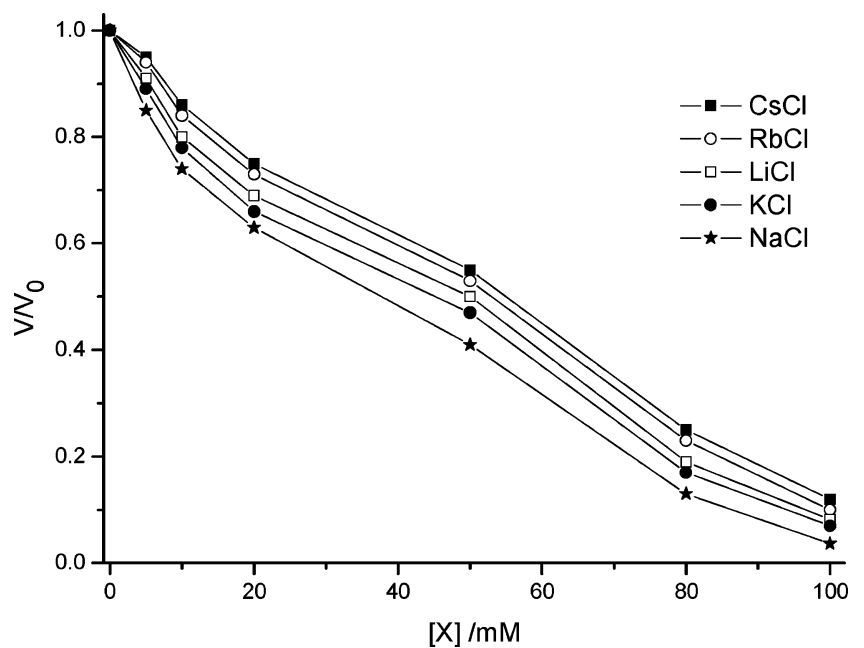

Figure 1. Swelling isotherm $\left(V / V_{0}\right)$ for DNA gels (1\% cross-linker) immersed in solutions of the monovalent ions $\mathrm{NaCl}, \mathrm{KCl}, \mathrm{LiCl}, \mathrm{RbCl}$, and $\mathrm{CsCl}$. Temperature $25^{\circ} \mathrm{C}, \mathrm{pH} 9$.

This is so because the precision increases when the same gel piece is studied at a stationary position in the test tube.

Static Fluorescence. For luminescence spectral measurements a Spex Fluorolog 111 was used in $90^{\circ}$ configuration. Emission spectra for the system of ethidium bromide and DNA were obtained with the monochromator set at appropriate wavelengths.

\section{Results and Discussion}

Monovalent and Divalent Metal Ions. In pure water, charged networks swell due to the osmotic pressure from the counterions, which originates from their translational entropy. The driving force of the swelling process is the presence of mobile osmotically active counterions. The volume changes of gels are associated with osmotic effects and not dehydration. On addition of a monovalent electrolyte, there is a progressive contraction of the gels as exemplified in Figure 1. Figure 1 shows the volume of the DNA gels in the presence of monovalent salts, $\mathrm{NaCl}, \mathrm{KCl}, \mathrm{LiCl}, \mathrm{RbCl}$, and $\mathrm{CsCl}(\mathrm{V})$, relative to the volume in $1 \mathrm{mM} \mathrm{NaOH}\left(V_{0}\right)$, as a function of salt concentration. When gels, preswollen in the $1 \mathrm{mM} \mathrm{NaOH}$, are placed into salt solutions at different concentrations, they shrink due to the screening effect of the salt and mainly due to the concentration difference of mobile ions inside the gel and the external solution governed by the Donnan equilibrium. In the presence of salt, the difference between ion concentrations inside and outside the gel is reduced. Consequently, the driving force of swelling decreases gradually with increasing salt concentration.

The nature of the monovalent counterion has only a moderate effect on the deswelling of DNA gels. The degree of collapse follows the order $\mathrm{Na}^{+}>\mathrm{K}^{+}>\mathrm{Li}+>\mathrm{Rb}^{+}>\mathrm{Cs}^{+}$, with the sodium ion showing the highest ability in collapsing DNA gels. Except for lithium, this dependence follows the Hofmeister series (lyotropic series), i.e., the observed deswelling effect increases with decreasing ionic radius $\mathrm{Li}<\mathrm{Na}<\mathrm{K}<\mathrm{Rb}<$ Cs. In fact, the order observed suggests that monovalent cations with a smaller atomic number are more efficient in the collapse of DNA gels. According to its smaller atomic number and its higher charge density, lithium demonstrates an unexpected behavior in this set of monovalent salts.

Recently, Horkay et al. showed that the deswelling degree of polyacrylate gels in pure water follows the series: $\mathrm{Li}^{+}>$ $\mathrm{Na}^{+}>\mathrm{K}^{+}>\mathrm{Cs}^{+}{ }^{65}$ Uncharged polyvinylpyrrolidone gels show

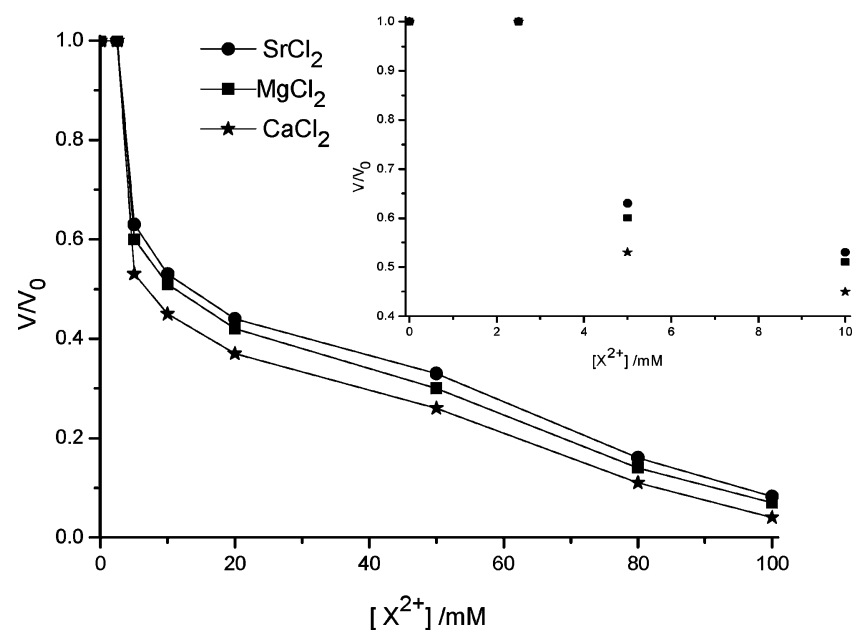

Figure 2. Swelling isotherm $\left(V / V_{0}\right)$ for DNA gels (1\% cross-linker) immersed in solutions of the divalent ions $\mathrm{CaCl}_{2}, \mathrm{MgCl}_{2}$ and $\mathrm{SrCl}_{2}$. The concentration range from $\left[\mathrm{X}^{2+}\right]=0$ to $10 \mathrm{mM}$ is also represented in detail (see inset). Temperature $25^{\circ} \mathrm{C}, \mathrm{pH} 9$.

the same cationic specificity. ${ }^{66}$ Moreover, in a study developed by Liu et al., dimethylacrylamide/2-acrylamide-2-methylpropyl sulfonate copolymer gels with different charge densities were immersed in salt solutions with different combinations of monovalent and divalent ions. The swelling degree was shown to depend on the counterion and to follow the Hofmeister series. ${ }^{67}$ The difference observed between $\mathrm{K}^{+}$and $\mathrm{Na}^{+}$was explained by different counterion condensation according to the Manning theory. ${ }^{67}$ Firestone and Siegel showed that the swelling degree for cationic methylmethacrylate/dimethylaminoethylmethacrylate (MMA/DMAEMA) (70/30) gels, immersed in salt solutions, was also dependent on the counterion and the swelling degree follows the Hofmeister series for anions. ${ }^{68}$ The effect of lithium seems to be rather specific for covalent DNA gels. The general trend seems to be that the swelling degree of polyelectrolyte gels with different counterions increases with decreasing counterion binding according to the Hofmeister series (for anions typically: high binding/low gel swelling and low binding/high gel swelling). However, the difference is typically quite small.

It is known that monovalent alkali cations are involved in the regulation of important biological processes and also influence the DNA compaction in living cells. Compaction of DNA by monovalent cations alone does not occur but can be promoted by an increase in the concentration of monovalent salts. ${ }^{69}$ Studies of the influence of the cation nature on the ability to induce DNA compaction in solution have been performed. ${ }^{70}$ In concentrated solutions of polyethylene glycol, the compaction potentials of different monovalent salts follows the order $\mathrm{Na}^{+}$ $>\mathrm{K}^{+}>\mathrm{Li}^{+}>\mathrm{Rb}^{+}>\mathrm{Cs}^{+}$, with sodium chloride being the most effective salt in promoting DNA compaction. The same sequential order has been found in the collapse of DNA gels when the effect of the same monovalent salts was studied.

The interaction between cross-linked DNA gels and divalent metal ions is illustrated in Figure 2. The deswelling on addition of the divalent salts $\mathrm{CaCl}_{2}, \mathrm{MgCl}_{2}$, and $\mathrm{SrCl}_{2}$ occurs at considerably lower salt concentrations, and the deswelling appears to be more pronounced, as compared with the monovalent metal ions mentioned above. Qualitatively, we expect this observation since in order to maintain electroneutrality, adding one divalent cation to the gel requires the exchange of two monovalent cations. However, in the presence of divalent metal ions the shrinking process of DNA gels seems to follow a different behavior; there is a marked deswelling at low metal 


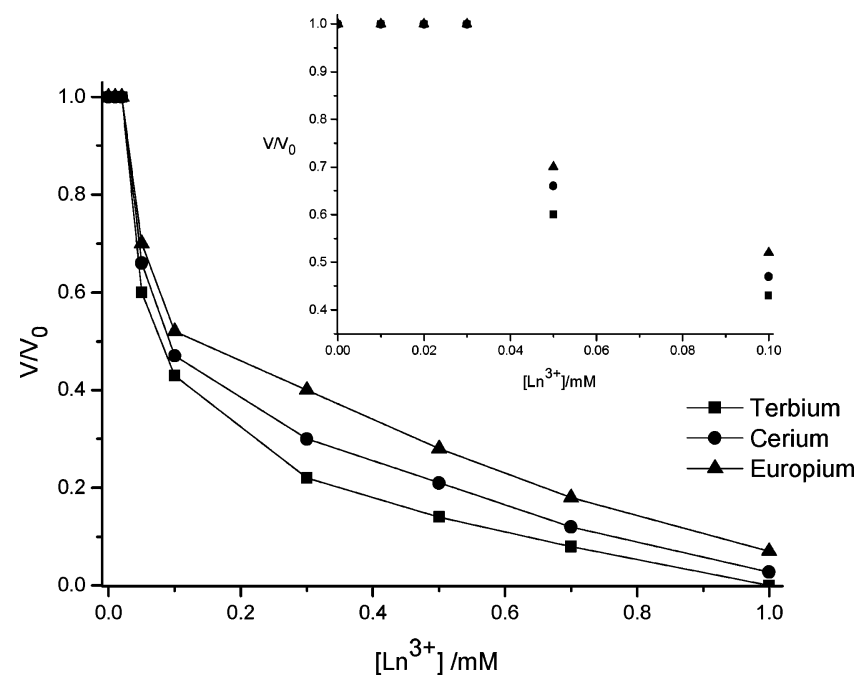

Figure 3. Swelling isotherm $\left(V / V_{0}\right)$ for DNA gels (1\% cross-linker) immersed in solutions of the trivalent ions terbium $\left(\mathrm{Tb}^{3+}\right)$, cerium $\left(\mathrm{Ce}^{3+}\right)$, and europium $\left(\mathrm{Eu}^{3+}\right)$. The concentration range from $\left[\mathrm{Ln}^{3+}\right]=$ 0 to $0.1 \mathrm{mM}$ is also represented in detail (see inset). Temperature 25 ${ }^{\circ} \mathrm{C}, \mathrm{pH} 9$.

ion concentrations followed by a region where deswelling occurs more progressively with concentration. This two-step process is suggested to involve, in a first step, a compaction of individual DNA chains induced by the presence of divalent ions and in a second step a general osmotic deswelling. This two-step process seems to be specific for DNA since there is no evidence in the literature for this kind of behavior involving other polyelectrolytes or polymers.

The collapse ratios for these gels show a trend in the order $\mathrm{CaCl}_{2}>\mathrm{MgCl}_{2}>\mathrm{SrCl}_{2}$, with calcium being the most effective ion on collapsing DNA gels. Tamura et al. studied the swelling ratios of poly $(\alpha$-hydroxyacrylic acid) (PHA) gels in solutions with six different divalent counterions. They showed that the gel deswelling occurred at a significantly lower concentration with $\mathrm{Ca}^{2+}$ than with $\mathrm{Mg}^{2+}$, referred to as a strong binding of $\mathrm{Ca}^{2+}$ to PHA, where $\alpha-\mathrm{OH}$ groups are believed to also be involved in complex formation. ${ }^{71}$

There are only a few studies reported where DNA structural transitions, similar to a DNA transition into a compact state, were induced by divalent metal ions in aqueous solutions at room temperature. ${ }^{72,73}$ In particular, Hackl and co-workers suggested that in solution, the mechanism of DNA compaction under the action of divalent ions is not dominated by electrostatics. According to these authors, the effectiveness of these ions to induce DNA compaction correlates with the affinity of these ions to DNA bases. ${ }^{74}$ Interaction with DNA bases may be responsible for DNA compaction due to the fact that this interaction can cause bends and reduction in the persistence length of DNA. $\mathrm{Ca}^{2+}$ and other divalent ions such as $\mathrm{Zn}^{2+}$ and $\mathrm{Mn}^{2+}$ should bind both to DNA phosphate groups and bases while $\mathrm{Mg}^{2+}$ ions only to phosphate groups of DNA. ${ }^{74}$ This may explain the observed difference in the DNA gel collapse ability between calcium and magnesium ions.

Trivalent Metal Ions. The swelling behavior of DNA gels was also studied in the presence of trivalent lanthanide ions. The lanthanide ions terbium $\left(\mathrm{Tb}^{3+}\right)$, cerium $\left(\mathrm{Ce}^{3+}\right)$, and europium $\left(\mathrm{Eu}^{3+}\right)$ were used at different concentrations. The results are shown in Figure 3. As for DNA condensation in solution, the effect of mono- and divalent ions is less pronounced in the gel collapse than that of trivalent lanthanide ions.

The addition of these ions has no large effect on the gel volume until $0.05 \mathrm{mM}$, a concentration at which the gel size

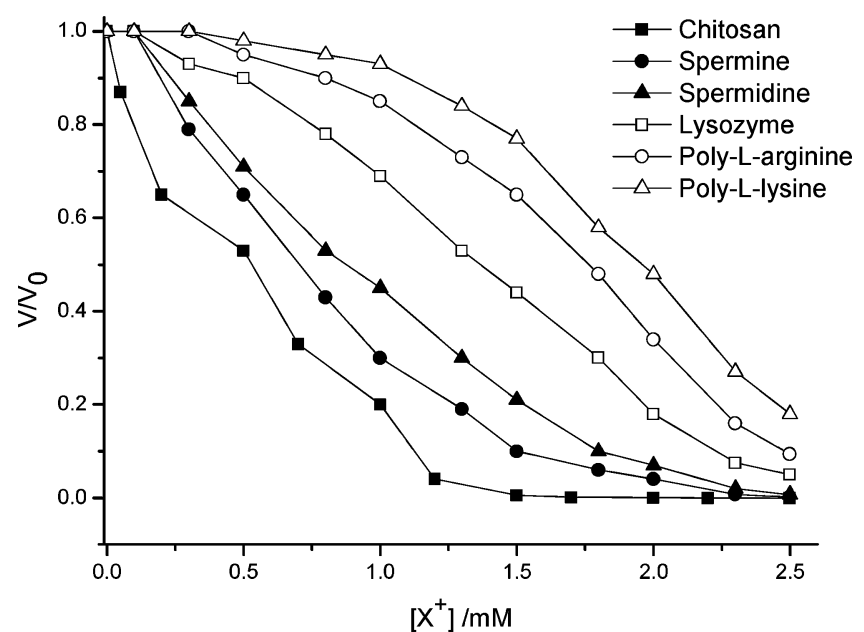

Figure 4. Swelling isotherm $\left(V / V_{0}\right)$ for DNA gels (1\% cross-linker) immersed in solutions of chitosan, spermine, spermidine, lysozyme, poly-L-lysine and poly-L-arginine. Temperature $25^{\circ} \mathrm{C}, \mathrm{pH}$ 6.5. Concentrations are presented in $\mathrm{mM}$ on a charge basis.

starts to decrease. For a better visualization of this region, see the inset of Figure 3. From this concentration is observed, first, an abrupt decrease in the gel volume and afterward, in the concentration range from 0.3 to $1 \mathrm{mM}$, the gel volume decreases more slowly with concentration. As in the presence of divalent metal ions, the deswelling of gels on addition of trivalent ions seems to follows a two-step process, suggested to involve a compaction of individual DNA chains. Clear differences in the efficiency of gel collapse were found between the trivalent ions, with terbium being the most efficient. Considerably lower concentrations of terbium are required to induce a decrease in the gel volume, when compared to cerium and europium, with the degree of collapse being in the order $\mathrm{Tb}^{3+}>\mathrm{Ce}^{3+}>\mathrm{Eu}^{3+}$. In a previous work, ${ }^{75}$ using luminescence spectroscopy, we found, in solution, a selective binding of the lanthanide ions to DNA involving the phosphate groups and also the nitrogen bases, such as guanine. In addition, we reported ${ }^{75}$ on the dehydration of the terbium ion on binding to DNA. The interaction of terbium ions with DNA involves the substitution of the bound water molecules by coordination with the phosphate groups of DNA. It seems that the same kind of interaction holds for the DNA gels in the presence of the same trivalent ions, but extended to higher concentrations than in solution. As in the DNA gels, terbium interacts in solution ${ }^{75}$ more strongly with DNA than cerium and europium ions. Also, the DNA coil-globule transition induced by trivalent metal ions observed in solution ${ }^{76}$ occurs at lower concentrations than in the network.

Polyamines and Other Polycations. The swelling behavior of DNA gels was studied in the presence of poly cationic species, which include chitosan, spermine (Spm), spermidine (Spd), lysozyme, poly-L-lysine (PL) and poly-L-arginine (PA). The results are summarized in Figure 4. Chitosan has the highest potential to induce collapse of DNA gels in the range of concentrations studied. The deswelling process starts already at very low concentrations of chitosan, $0.1 \mathrm{mM}$. In similar studies, using other cations, higher concentrations of the cosolute are needed. This is the case of the polyamines, which are needed in higher amounts to induce the collapse of the gels. Moreover, the cationic protein lysozyme has the capability to collapse DNA gels but to a smaller extent than the agents mentioned. The addition of the polypeptides, poly-L-arginine and poly-L-lysine, leads to a gel deswelling but at higher concentrations. No significant changes in the volume of the gels were observed 


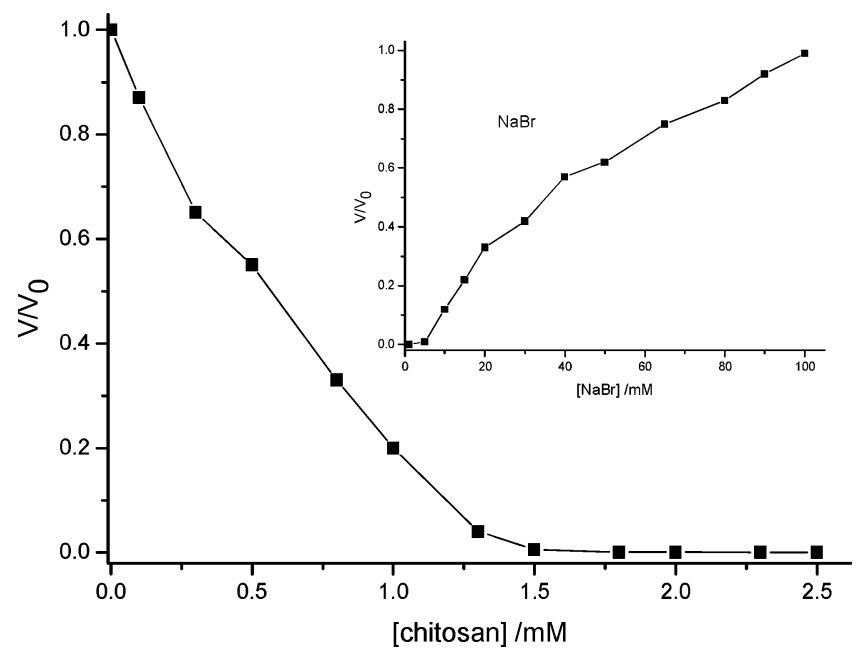

Figure 5. Swelling isotherm $\left(V / V_{0}\right)$ for DNA gels (1\% cross-linker) pre-collapsed first in solutions of chitosan and then immersed in solutions of $\mathrm{NaBr}$. Temperature $25^{\circ} \mathrm{C}, \mathrm{pH}$ 6.5. Chitosan concentrations are presented in $\mathrm{mM}$ on a charge basis.

until $0.5 \mathrm{mM}$. Poly-L-lysine is the weakest agent in the collapse of DNA gels.

The properties of chitosan in solution depend on its molecular weight, the degree of deacetylation and $\mathrm{pH}$. Since the $\mathrm{pKa}$ of chitosan is about 6.5 , chitosan is fully protonated at low $\mathrm{pH}$ $(3.5-4)$, but as the $\mathrm{pH}$ is increased, more of the polyelectrolyte segments will become uncharged. At acidic $\mathrm{pH}$, according to the general electrostatic effect, the positively charged chitosan associate to the DNA networks and condenses it, to an extent which is dependent on the chitosan concentration. When the gels collapsed, due to the addition of chitosan, are immersed in $\mathrm{NaBr}$ solutions at different concentrations, they reswell due to the screening effect of the salt, as shown in Figure 5. This can be explained by a competition effect where the multivalent counterions are significantly replaced by the monovalent ions. The $V / V_{0}$ returned to $90 \%$ and $100 \%$ of the initial state; thus, swelling-deswelling appears to be quite reversible. As chitosan is a nontoxic and easily biodegradable polymer, delivery systems based on chitosan are being used for a wide range of drugs. ${ }^{77}$ This reversible swelling-shrinking process will increase the potential of chitosan as a nonviral vehicle for transferring drugs into cells.

The polyamines spermine $\left(\mathrm{Spm}^{4+}\right)$ and spermidine $\left(\mathrm{Spd}^{3+}\right)$ are essentially fully protonated at physiological $\mathrm{pH}$ (i.e., ammonium ions). Comparison between the swelling curves of the gels in the presence of spermine and spermidine could be made in terms of the different charges carried by these cationic species. The higher charge of spermine compared to spermidine evidently makes spermine bind more strongly to DNA with a concomitant higher gel collapse potential. We also checked for the reversible swelling/shrinking transition by the addition of $\mathrm{NaBr}$, at different concentrations, to the gels collapsed by the polyamines. In the same way as with chitosan, the swelling ratio, $V / V_{0}$, returned to the initial state (data not shown).

As a protein we used lysozyme here, an enzyme that breaks down bacterial cell walls by hydrolyzing the polysaccharide component of the cell wall. This small globular protein is positively charged in acidic medium. At the $\mathrm{pH}$ we used, lysozyme has a net positive charge of eight. Due to this high number of positive charges, we expected a very efficient collapse of DNA gels by lysozyme. Instead, it is a weaker agent in the deswelling when compared to chitosan and the polyamines. A

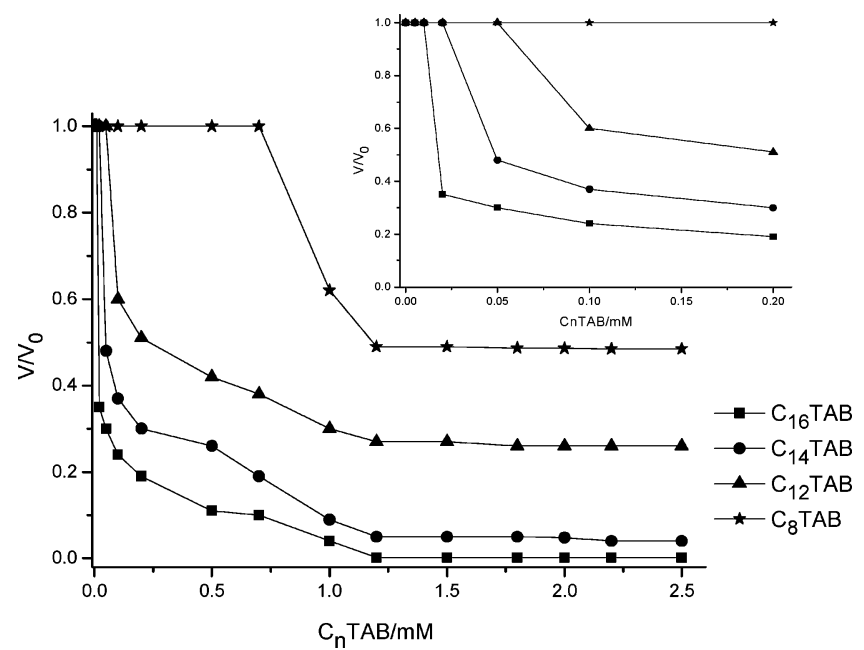

Figure 6. Swelling isotherm $\left(V / V_{0}\right)$ for DNA gels (1\% cross-linker) immersed in solutions of the cationic surfactants $\mathrm{C}_{16} \mathrm{TAB}, \mathrm{C}_{14} \mathrm{TAB}$, $\mathrm{C}_{12} \mathrm{TAB}$, and $\mathrm{C}_{8} \mathrm{TAB}$. The concentration range from $\left[\mathrm{C}_{n} \mathrm{TAB}\right]=0$ to $0.2 \mathrm{mM}$ is also represented in detail (see inset). Temperature $25^{\circ} \mathrm{C}$, $\mathrm{pH} 9$.

considerably larger concentration of lysozyme was needed to reach a corresponding collapse of the gel.

Regarding the poly amino acids, the $\alpha-\mathrm{COOH}$ and $\alpha-\mathrm{NH}_{2}$ groups in amino acids are capable of ionizing, as are the other acid and basic R-groups of the amino acids. The pKa values for arginine and lysine are $\mathrm{p} K_{1}(\mathrm{COOH})=1.8, \mathrm{p} K_{2}\left(\mathrm{NH}_{2}\right)=$ 9.0, and $\mathrm{p} K_{3}$ (radical group) $=12.5$ and $\mathrm{p} K_{1}(\mathrm{COOH})=2.2$, $\mathrm{p} K_{2}\left(\mathrm{NH}_{2}\right)=9.2$, and $\mathrm{p} K_{3}$ (radical group) $=10.8$, respectively. The observed difference in the swelling isotherms of DNA gels in the presence of poly-L-arginine and poly-L-lysine could be due to the presence of an additional imino group in poly-Larginine. This imino group increases the extent of association, and thus, the collapse of the gels occurs at slightly lower polyL-arginine concentrations.

For a deeper understanding of the mechanism of binding of polycations to DNA, further experiments on the basis of modeling will be reported soon.

Cationic Surfactants. Figure 6 shows swelling isotherms for DNA gels on addition of a number of cationic surfactants. As can be seen, the surfactants have no effect at lower concentrations but there is a marked deswelling at higher concentrations, which becomes more important the longer the surfactant alkyl chain. We note that the concentration of onset of deswelling varies by orders of magnitude between different surfactants. We also note that the plateau value obtained at high surfactant concentrations is lower the longer the alkyl chain length. The pronounced chain length dependences directly suggest a dominant role of surfactant self-assembly.

In the bulk phase and at low concentrations, the surfactant molecules are dissolved as unimers, whereas at higher surfactant concentrations a self-assembly into aggregates occurs. For the single-chain surfactants studied here, the aggregates formed in this self-assembly are commonly spherical micelles with micelle formation starting at a well-defined concentration, the critical micelle concentration $(\mathrm{cmc})$. The $\mathrm{cmc}$ depends on the chemical structure of the surfactant, surfactants with longer hydrophobic tails having lower cmc values. In the presence of an oppositely charged polyelectrolyte, the micelle formation of an ionic surfactant is strongly facilitated leading to a major lowering of the $\mathrm{cmc}$; the $\mathrm{cmc}$ in the presence of a polymer is often referred to as the critical association concentration, cac. The stabilization of micelles due to an oppositely charged polyelectrolyte is 
mainly an entropic effect, due to a release of counterions. Therefore, the critical aggregation concentration, for the surfactant in the presence of DNA, cac, is lower than the critical micellization concentration, cmc. The fact that the cationic surfactant binding occurs preferentially to anionic polyelectrolytes of high charge density further enhances this behavior. ${ }^{78,79}$

The DNA gels are highly swollen due to the osmotic pressure arising from the counterions, which are confined to the gel. After the immersion of the swollen DNA gels in the solutions of the oppositely charged surfactants, the surfactant ions migrate into the network and replace the network counterions, which are released. In comparison with the regular micellization involving counterion binding, this process is as for bulk solution extremely favorable from the point of view of translational entropy of the counterions, due to the release of condensed counterions of both polymer network and surfactant micelles. Adsorption of a considerable amount of $\mathrm{C}_{n} \mathrm{TA}^{+}$ions leads to a transition of the swollen network to the collapsed state. The main reason for this transition is thus the aggregation of surfactant ions within the DNA gel due to hydrophobic interactions between their hydrocarbon chains. As a consequence of this, the mobile counterion concentration in the network decreases, leading to a significant decrease in the internal osmotic pressure in the gel. Furthermore, the surfactant aggregates will act as multivalent counterions and by ion correlation effects contribute to the contraction of the gel. ${ }^{80,81}$

In particular, these results for the different alkyl chain lengths confirm that the deswelling occurs below the normal critical micelle concentration of the surfactant. The cmc values for $\mathrm{C}_{16^{-}}$ $\mathrm{TAB}, \mathrm{C}_{14} \mathrm{TAB}, \mathrm{C}_{12} \mathrm{TAB}$, and $\mathrm{C}_{8} \mathrm{TAB}$ are $0.9,0.23,15$, and 144 $\mathrm{mM}$, respectively. We found that the surfactants induce the volume transition starting at a certain rather well-defined concentration $\sim 0.02 \mathrm{mM}$ for $\mathrm{C}_{16} \mathrm{TAB},{ }^{82} \sim 0.05 \mathrm{mM}$ for $\mathrm{C}_{14^{-}}$ $\mathrm{TAB}, \sim 0.1 \mathrm{mM}$ for $\mathrm{C}_{12} \mathrm{TAB}$, and $\sim 1 \mathrm{mM}$ for $\mathrm{C}_{8} \mathrm{TAB}$; these values are similar to the observed cac values in bulk solution. The initial plateau, indicating no volume transition of the gels, in the concentration range under study, is thus very narrow for $\mathrm{C}_{16} \mathrm{TAB}$ but increases for $\mathrm{C}_{14} \mathrm{TAB}$ and $\mathrm{C}_{12} \mathrm{TAB}$, while $\mathrm{C}_{8} \mathrm{TAB}$ shows a very large plateau. This effect was also shown for EHEC gels in solutions with alkyl-TABr: $\mathrm{s}^{83}$ and for HEC gels in solutions with sodium alkyl sulfates. ${ }^{7}$ The gel collapse disappears when the hydrophobic tail is too short.

The differences in the swelling ratio, $V / V_{0}$, and also aggregate size should at least partly be due to differences in the concentration of the free surfactant, which acts as a screening electrolyte; as noted above, salt addition to collapsed gels leads to gel swelling. However, the degree of binding is also higher for a surfactant with a longer hydrophobic tail, because of larger micelles. This contributes to a larger collapse of the gels.

In addition to the studies of the steady-state gel volumes, the kinetics of DNA gel deswelling was also studied using surfactants with different hydrocarbon chains. Figure 7 shows the transient volume changes of a DNA gel piece for different concentrated solutions of the cationic surfactants $\mathrm{C}_{16} \mathrm{TAB}, \mathrm{C}_{14^{-}}$ $\mathrm{TAB}, \mathrm{C}_{12} \mathrm{TAB}$, and $\mathrm{C}_{8} \mathrm{TAB}$. The range of concentration used was chosen according to the critical micellization concentration (cmc) values of the surfactants. A slowing down of the collapse process was observed on using surfactants with longer hydrophobic tails. In fact, $\mathrm{C}_{16} \mathrm{TAB}$ presents the slowest kinetics in contrast with the behavior for the DNA gel- $\mathrm{C}_{8} \mathrm{TAB}$ system, reaching its collapse equilibrium faster than the other systems studied. As the diffusion of surfactant to the DNA chains inside the gel is dependent on both the surfactant ion mobility and the surfactant activity (equalling the free surfactant concentration),

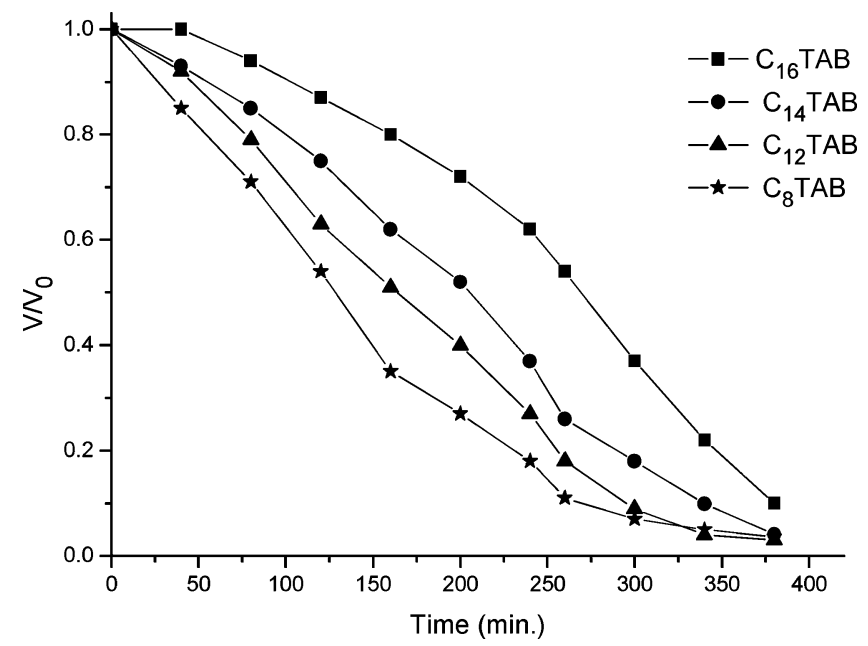

Figure 7. Transient volume changes $\left(V / V_{0}\right)$ of a DNA gel ( $1 \%$ crosslinker) immersed in solutions of $1 \mathrm{mM}$ of the cationic surfactants $\mathrm{C}_{16^{-}}$ $\mathrm{TAB}, \mathrm{C}_{14} \mathrm{TAB}, \mathrm{C}_{12} \mathrm{TAB}$, and $\mathrm{C}_{8} \mathrm{TAB}$. Temperature $25^{\circ} \mathrm{C}, \mathrm{pH} 9$.

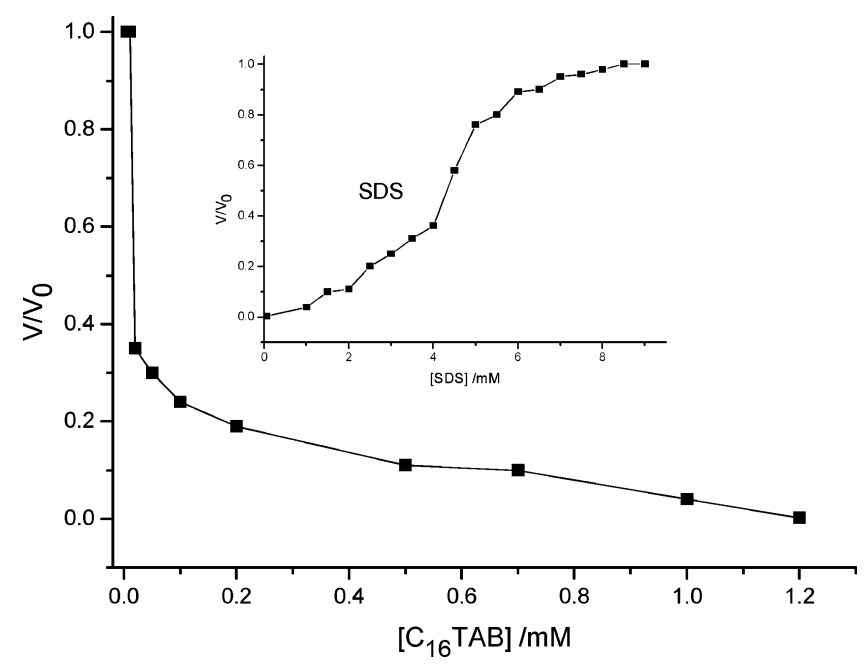

Figure 8. Swelling isotherm $\left(V / V_{0}\right)$ for DNA gels (1\% cross-linker) pre-collapsed first in solutions of the cationic surfactant $\mathrm{C}_{16} \mathrm{TAB}$ and then immersed in solutions of the anionic surfactant SDS. Temperature $25^{\circ} \mathrm{C}, \mathrm{pH} 9$.

there are two possible explanations for this observation. The first is related to the translational diffusion of an individual surfactant molecule, which becomes slower for a longer hydrophobic tail, and the second related to the fraction of fastdiffusing surfactant monomers, which is lower in case of a lower $\mathrm{cmc} / \mathrm{cac}$. The latter, varying by orders of magnitude between surfactants, is certainly the most important effect. Isogai et al. also found, in another gel/surfactant system, interesting changes with increasing alkyl chain length. ${ }^{84}$

We also investigated the effect of the addition of an anionic surfactant to DNA gels collapsed by a cationic surfactant, as this would illustrate the degree of reversibility of the swelling process. This study concerned the addition of different concentrations of a cationic surfactant, $\mathrm{C}_{16} \mathrm{TAB}$, followed, after gel collapse, by the addition of different concentrations of an anionic surfactant, sodium dodecyl sulfate (SDS). Figure 8 shows the behavior when collapsed DNA gels were immersed in SDS solutions. The most important aspect is that the relative $\mathrm{V} / \mathrm{V}_{0}$ returned to between $90 \%$ and $100 \%$ of the initial state. Thus, the swelling of DNA gels appears to be reversible. We argue that, as in our previous studies of the behavior of DNA in the presence of a mixed cationic-anionic surfactant system, ${ }^{85}$ the interaction between the two surfactants is stronger than that 


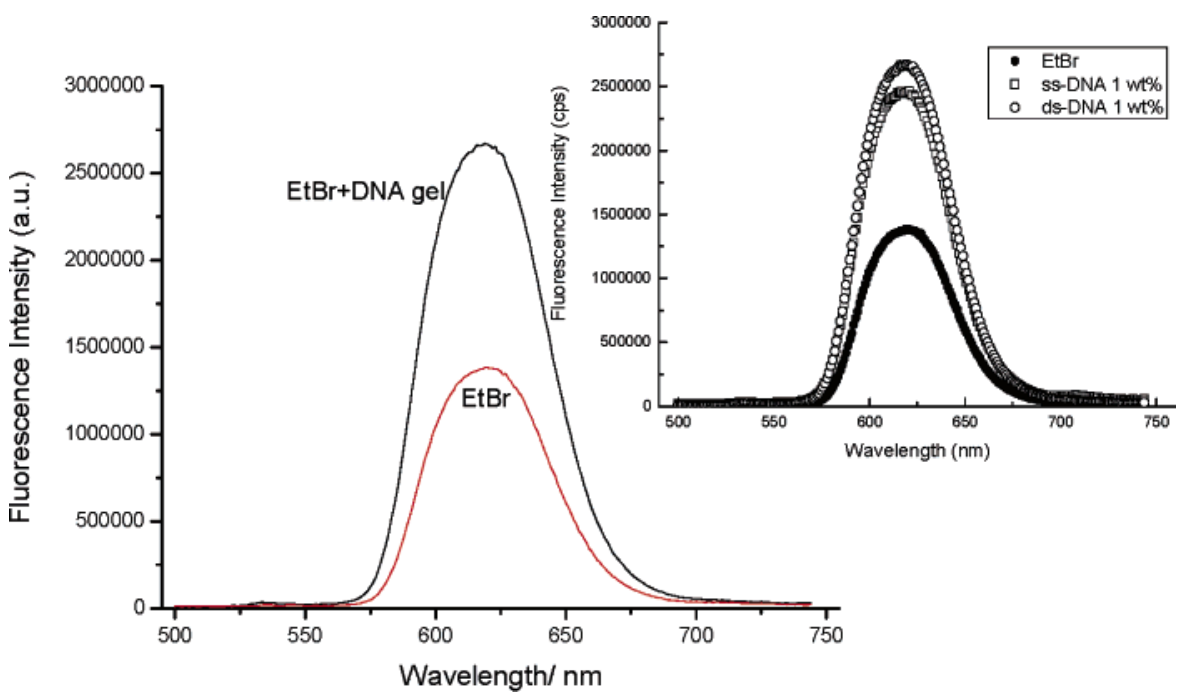

Figure 9. Fluorescence spectra of ethidium bromide in the absence and presence of DNA gel (1\% cross-linker) collapsed by chitosan, and in the presence of reference solutions of ds-DNA $1 \%$ and ss-DNA $1 \%$ (inset). Temperature $25^{\circ} \mathrm{C}$.

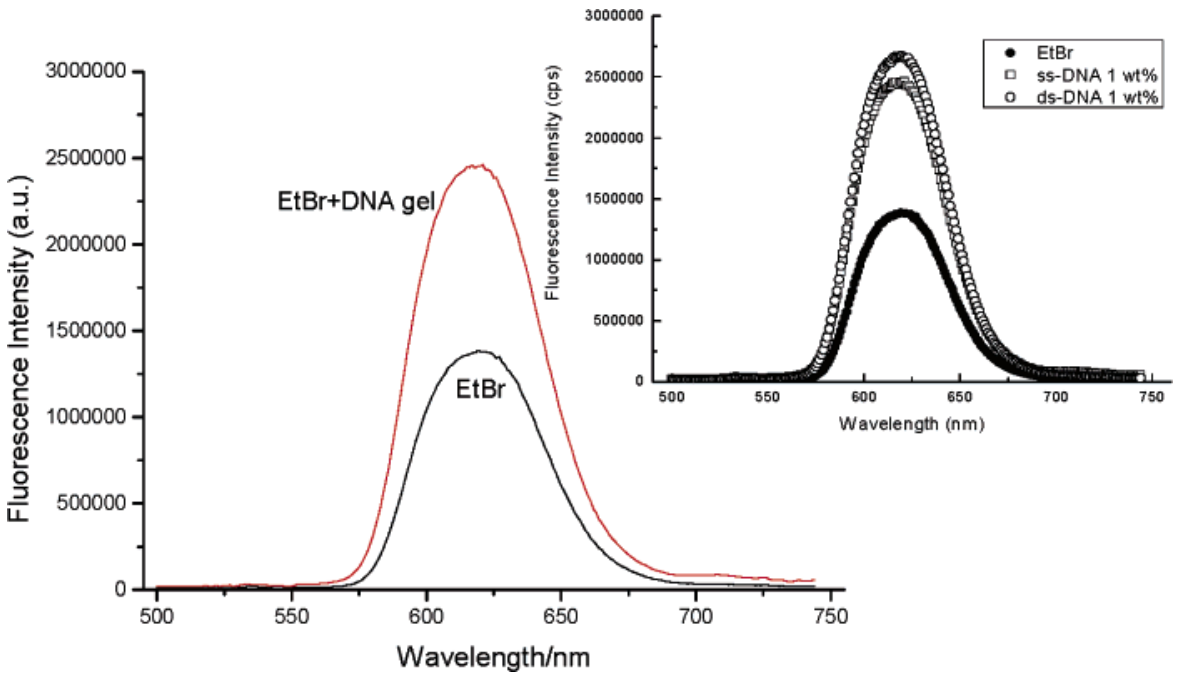

Figure 10. Fluorescence spectra of ethidium bromide in the absence and presence of DNA gel (1\% cross-linker) collapsed by terbium, and in the presence of reference solutions of ds-DNA $1 \%$ and ss-DNA $1 \%$ (inset). Temperature $25{ }^{\circ} \mathrm{C}$.

between a cationic surfactant and DNA; in these studies we found that DNA after compaction by a cationic surfactant is decompacted on addition of an anionic one. The dynamic deswelling-swelling process could be useful in the control of the release rate of solutes from gels via "on-off" switching. ${ }^{86}$

In the system with cationic and anionic surfactant described above, we predict the formation of mixed aggregates of $\mathrm{C}_{16^{-}}$ TAB and SDS. Since we added SDS to the DNA gels collapsed by $\mathrm{C}_{16} \mathrm{TAB}$, there is an excess of SDS in the final swollen gel. Mixed surfactant aggregates like vesicles will then be formed. To confirm the existence of ordered structures, the swollen DNA gels were checked for optical birefringence by positioning them between crossed polarizers. The samples appeared birefringent (anisotropic) indicating the existence of ordered structures.

On the DNA Conformation in the Collapsed Gels. Information about the conformation of the DNA molecules in the collapsed gels was obtained by fluorescence measurements using ethidium bromide, as a fluorescent probe. Ethidium bromide is a dye that binds to double-stranded DNA by intercalation between the base pairs and is characterized by a high quantum yield of fluorescence. ${ }^{87}$ In a previous study, ${ }^{82}$ we found evidence for a double helix arrangement of DNA in the cross-linked DNA network in the swollen state. In the present study, we checked for the conformation of DNA in the DNA gels collapsed by the cationic agents mentioned above. We used the collapsed gel obtained by the addition of the most concentrated solution of the cationic agent. The conformation of DNA in the gels collapsed on the addition of the different classes of surfactants, mono- and divalent ions, chitosan, spermine, spermidine, lysozyme, poly-L-lysine, and poly-L-arginine was found to be the same. Thus, a double-stranded conformation of the DNA helices was found for all these DNA gel systems. As an example, we show the data for the DNA gels collapsed by chitosan; the same kind of data was obtained for the DNA gels collapsed by the other cationic species. Figure 9 shows the fluorescence spectrum of ethidium bromide in the presence of a collapsed DNA gel for a DNA concentration of $1 \mathrm{wt} \%$; as a reference and for the same concentration, the spectrum is represented in the absence of the DNA gel. In the inset of this figure, the spectra of ethidium bromide in aqueous solution and in aqueous solutions of double-stranded DNA and singlestranded DNA, at the same concentration as in the gel (1 wt $\%)$, are shown. When EtBr is bound to nucleic acids, a marked enhancement in its fluorescence is observed; however, this increase depends on the configuration of the DNA. As ethidium bromide in the presence of the collapsed DNA gels presents the same fluorescence intensity as that in the solution of doublestranded DNA, we can assume that ethidium bromide binds to 
the collapsed gel in the same way as it binds to ds-DNA. Quantitatively, the maximum fluorescence intensity, at $626 \mathrm{~nm}$, for both reference DNA solutions are for ss-DNA and ds-DNA respectively, 2.37345 E6 and 2.57807 E6. In Figure 9, the EtBrDNA gel has a fluorescence intensity of 2.599107 E6 at 626 nm confirming a double-stranded conformation. We conclude that, for these collapsed gels, DNA molecules are in their double-stranded conformation.

A quite different behavior was observed for the DNA gels collapsed by the trivalent metal ions. Figure 10 shows the fluorescence spectrum of ethidium bromide in the presence of a DNA gel collapsed by terbium, for a DNA concentration of $1 \mathrm{wt} \%$; as reference and for the same concentration, the spectrum is represented in the absence of the DNA gel. In the inset of this figure, the spectra of ethidium bromide in the aqueous reference solutions described above are shown. In this case, ethidium bromide presents the same fluorescence intensity as in the solution of single-stranded DNA. In Figure 10, the gel presents a value of 2.38251 E6 confirming a single-stranded conformation of DNA.

We conclude that, for the gels collapsed by terbium, DNA molecules are in their single-stranded conformation. The same kind of DNA conformation was found for gels collapsed by the addition of cerium and europium ions (data not shown).

Terbium is known to interact with DNA by destabilizing the double helix through the breaking of hydrogen bonds, which leads to a lowering of the melting point $\left(T_{\mathrm{m}}\right) .{ }^{88}$ Once a base pair of a turn in a double helix is separated, terbium can bind directly to the bases. Single-stranded DNA molecules have the hydrophobic bases more exposed than double-stranded DNA, which can lead to the formation of more binding sites, along with strong electrostatic interactions. In a previous study, ${ }^{75}$ we have reported on the transition from double to single-stranded DNA molecules in solution on adding terbium. We found that this transition was $\mathrm{pH}$ dependent; at $\mathrm{pH} 4.7$ and 7, the double helix arrangement was maintained, and the main interaction involves the negatively charged phosphate groups, while at $\mathrm{pH}$ 9 there is denaturation of the DNA. This suggests that at $\mathrm{pH} 9$, terbium denatures DNA and binds to single strands, probably by interacting also with the nitrogen bases. Changes in the mechanism of binding with $\mathrm{pH}$ showed differences in the number of water molecules in the coordination sphere of terbium. ${ }^{75}$ As mentioned above, it seems that the same kind of mechanism holds for the cross-linked DNA networks, in the presence of these lanthanide ions. In the gel formation process described in the experimental section, we have used $\mathrm{pH} 9$ in the cross-linking reaction. The use of this $\mathrm{pH}$ value favors the DNA denaturation in the presence of terbium, cerium and europium, according to the mechanism of binding described above.

\section{Conclusions}

We have demonstrated that the gel swelling experiment is a simple and useful method to study DNA-cosolute interactions; this approach of elucidating polymer-cosolute interactions has previously been successfully elaborated by Piculell and coworkers. ${ }^{7,19,83}$ Changes in the binding of cationic agents to DNA are accompanied by changes in the gel volume. The deswelling of the DNA gels on addition of different metal ions does not follow the pronounced surfactant-induced shrinking behavior but appears to be of a more progressive type; it occurs at lower ion concentrations with increasing valency of the counterion. In the presence of divalent metal ions, the deswelling can be described as a two-step process. The effect of the trivalent metal ions is more pronounced than that of the mono- and divalent ions. In the presence of the lanthanide ions, the DNA molecules in the gel are in their single-stranded conformation. The addition of different cationic agents such as chitosan, polyamines and charged proteins leads to a strong gel collapse. Introducing salt solutions at different concentrations to the collapsed gels shows that the swelling/deswelling process is reversible.

The gel swelling behavior in solutions of cationic surfactants is governed by the surfactant properties, the surfactant selfassembly being the most important factor. It is generally straightforward to detect the onset of surfactant binding in cases where this occurs at a critical association concentration (cac). The method relies only on the appearance of a drastic volume change of the gel starting at this concentration. The DNA gels bind alkyltrimethylammonium bromides, with the collapse of the gels depending on the length of the hydrophobic tail, and being facilitated by the surfactant hydrophobicity. The swelling/ deswelling transition on addition of the cationic surfactant, $\mathrm{C}_{16^{-}}$ $\mathrm{TAB}$, followed by the addition of the anionic surfactant SDS, appears to be reversible. The same holds for the coil-globule transition, observed for DNA in solution and in the presence of the same surfactants.

Since a nonviral gene delivery system in gene therapy is expected to be a preferred choice in the future, these features on the DNA gel swelling can make them useful for the development of efficient and safe systems. In fact, the collapse of convenient DNA gels by interaction with oppositely charged species may represent a potential tool, in the gene therapy field, allowing the condensation and transfer of a considerable amount of DNA into cells.

Acknowledgment. We are grateful to Fundação para a Ciência e a Tecnologia (FCT (SFRH/BD/16736/2004), EU Research Training Network, CIPSNAC (Contract No. MRTNCT-2003-504932), FEDER-POCTI/QUI/58689/2004, and the Swedish Science Research Council (VR) for financial support. The authors also thank Håkan Wennerström for helpful discussions.

\section{References and Notes}

(1) Kokufuta, E.; Suzuki, H.; Yoshida, R.; Yamada, K.; Hirata, M.; Kaneko, F. Langmuir 1998, 14, 788-795.

(2) Lee, W.; Hsu, C. J. App. Polym. Sci. 1999, 74, 3242-3253.

(3) Eichenbaum, G. M.; Kiser, P. F.; Shah, D.; Meuer, W. P.; Needham, D.; Simon, S. A. Macromolecules 2000, 33, 4087-4093.

(4) Annaka, M.; Ogata, Y.; Nakahira, T. J. Phys. Chem. B 2000, 104, $6755-6760$.

(5) Zhang, J.; Peppas, N. A. Macromolecules 2000, 33, 102-107.

(6) Zhao, B.; Moore, J. S. Langmuir 2001, 17, 4758-4763.

(7) Sjöström, J.; Piculell, L. Langmuir 2001, 17, 3836-3843.

(8) Sayil, C.; Okay, O. J. App. Polym. Sci. 2002, 83, 1228-1232.

(9) Kiser, P. F.; Wilson, G.; Needham, D. Nature 1998, 394, 459462.

(10) Akala, E. O.; Kopeckova, P.; Kopecek, J. Biomaterial. 1998, 19, $1037-1047$

(11) Torres-Lugo, M.; Peppas, N. A. Macromolecules 1999, 32, 66466651 .

(12) Tanaka, T. Hydrogels. In Encyclopedia of Polymer Science and Technology; Mark, H. F., Kroschwitz, J. I., Eds.; New York: Wiley, 1985; pp 514-531.

(13) Horkay, F.; Tasaki, I.; Basser, P. J. Biomacromolecules 2000, 1, 84-90.

(14) Yodhida, R.; Uchida, K.; Kaneko, Y.; Sakai, K.; Kikuchi, A.; Sakurai, Y.; Okano, T. Nature 1995, 374, 240-242.

(15) Gotoh, T.; Nakatani, Y.; Sakohara, S. J. J. Appl. Polym. Sci. 1998, 69, 895-906.

(16) Lee, K. K.; Cussler, E. L.; Marchetti, M. Chem. Eng. Sci. 1990, 45, 766-767.

(17) Tanaka, T. Phys. Rev. Lett. 1978, 40, 820-823.

(18) Ishihhara, K.; Muramoto, N.; Shinohara, I. J. Appl. Polym. Sci. 1984, 29, 211-217. 
(19) Sjöström, J.; Piculell, L. Colloids Surf., A 2001, 429, 183-185.

(20) Mironov, A. V.; Starodoubtsev, S. G.; Khokhlov, A. R. Macromolecules 1998, 31, 7698-7705.

(21) Khokhlov, A. R.; Kramarenko, E. Yu.; Makhaeva, E. E.; Starodoubtsev, S. G. Macromol. Chem. Theory Simul. 1992, 1, 105-118.

(22) Philippova, O. E.; Hourdet, D.; Audebert, R.; Khokhlov, A. R. Macromolecules 1996, 29, 2822-2830.

(23) Starodoubtsev, S. G.; Churochkina, N. A.; Khokhlov, A. R. Langmuir 2000, 16, 1529-1534.

(24) Bronstein, L. M.; Platonova, O. A.; Yakunin, A. N.; Yanovskaya, I. M.; Valetsky, P. M. Langmuir 1998, 14, 252-259.

(25) Khokhlov, A. R.; Kramarenko, E. Yu.; Makhaeva, E. E.; Starodoubtsev, S. G. Macromolecules 1992, 25, 4779-4783.

(26) Philippova, O. E.; Starodoubtsev, S. G. J. Polym. Sci., Part B: Polym. Phys. 1993, 31, 1471-1476.

(27) Philippova, O. E.; Chtcheglova, L. A.; Karybiants, N. S.; Khokhlov, A. R. Polym. Gels Networks 1998, 6, 409-421.

(28) Starodoubtsev, S. G.; Dembo, A. T.; Dembo, K. A. Langmuir 2004, 20, 6599-6604.

(29) Irie, M. Adv. Polym. Sci. 1990, 94, 28-67.

(30) Gehrke, S. H; Lee, P. I. Hydrogels for Drug Delivery Systems. In Specialized Drug Delivery Systems; Tyle, P., Ed.; Marcel Dekker: New York, 1990; pp 333-392.

(31) Eichenbaum, G. M.; Kiser, P. F.; Dobrynin, A. V.; Simon, S. A.; Needham, D. Macromolecules 1999, 32, 4867-4878.

(32) Kazanskii, K. S.; Dubrovskii, S. A. Adv. Polym. Sci. 1992, 97, 104109

(33) Takezawa, T.; Mori, Y.; Yoshizato, K. Biotechnology 1990, 8, 854856

(34) Liu, F.; Tao, G. L.; Zhuo, R. X. Polym. J. 1993, 25, 561-569.

(35) Okano, T.; Kikuchi, A.; Sakurai, Y.; Takei, Y.; Ogata, N. J. Controlled Release 1995, 36, 125-233.

(36) Khokhlov, A. R.; Starodubtzev, S. G.; Vasilevskaya, V. V. Adv. Polym. Sci. 1993, 109, 123-172.

(37) Barrat, J. L.; Joanny, J. F. In Advances in Chemical Physics Prigogine, I., Rice, S. A., Eds.; John Wiley: New York, 1997; Vol. 1, p 94.

(38) Hill, T. L. An Introduction to Statistical Thermodynamics; Dover: New York, 1986

(39) Wilder, J.; Vilgis, T. A. Phys. Rev. E 1998, 57, 6865-6874.

(40) Vilgis, T. A.; Wilder, J. Comput. Theor. Polym. Sci. 1998, 8, 6173

(41) Frusawa, H.; Hayakawa, R. Phys. Rev. E 1998, 58, 6145-6154

(42) Firestone, B. A.; Siegel, R. A. J. Appl. Polym. Sci. 1991, 43, $901-$ 914

(43) Moe, S. T.; Skjåk-Braek, G.; Elgsaeter, A.; Smirdsrød, O. Macromolecules 1993, 26, 3589-3597.

(44) Hansson, P.; Schneider, S.; Lindman, B. Prog. Colloid Polym. Sci. 2000, 115, 342-346.

(45) Khandurina, Y. V.; Rogacheva, V. B.; Zezin, A. B.; Kabanov, V. A. Polym. Sci. 1994, 36, 184-189.

(46) Hansson, P. Langmuir 1998, 14, 4059-4064.

(47) Hansson, P.; Schneider, S.; Lindman, B. J. Phys. Chem. B 2002 106, 9777-9793.

(48) Yoshikawa, K.; Takahashi, M.; Vasilevskaya, V. V.; Khokhlov, A. R. Phys. Rev. Lett. 1996, 76, 3029-3031.

(49) Iwataki, T.; Kidoaki, S.; Sakaue, T.; Yoshikawa, K.; Abramuchuk,

S. S. J. Chem. Phys. 2004, 120, 4004-4011.

(50) Yamasaki, Y.; Yoshikawa, K. J. Am. Chem. Soc. 1997, 119, 1057110578 .

(51) DeRouchey, J.; Netz, R. R.; Rädler, J. O. Eur. Phys. J. E 2005 , $16,17-28$.

(52) Watson, J. D.; Hopkins, N. H.; Roberts, J. W.; Steitz, J. A.; In Molecular Biology of the Gene, 4th ed.; Benjamin Publishing Company: Menlo Park, CA, 1987.
(53) Widom, J.; Baldwin, R. L. J. Mol. Biol. 1980, 144, 431-453.

(54) Sen, D.; Cothers, D. M. Biochemistry 1986, 25, 1495-1503.

(55) Arscott, P. G.; Ma, C.; Wenner, J.; Bloomfield, V. A. Biopolymers 1995, 36, 345-365.

(56) Khan, M. O.; Jönsson, B. Biopolymers 1999, 49, 121-125.

(57) Zou, L. L.; Huang, L.; Hayes, R. L.; Black, C.; Qiu, Y. H.; Perez-

Polo, J. R.; Le, W.; Clifton, G. L. Gene Ther. 1999, 6, 994-1005.

(58) Nchinda, G.; Zschörnig, O.; Überla, K. J. Gene Med. 2003, 5, 712722 .

(59) Köping-Höggård, M.; Mel'nikova, Y. S.; Vårum, K. M.; Lindman, B.; Artursson, P. J. Gene Med. 2003, 5, 130-141.

(60) Tokunaga, M.; Hazemoto, N.; Yotsuyanagi, T. Int. J. Pharmacol. 2004, 269, 71-80.

(61) Percot, A.; Briane, D.; Coudert, R.; Reynier, P.; Bouchemal, N.; Lièvre, N.; Hantz, E.; Salzmann, J. L.; Cao, A. Int. J. Pharmacol. 2004 278, 143-163.

(62) Chittimalla, C.; Zammut-Italiano, L.; Zuber, G.; Behr, J. P. J. Am Chem. Soc. 2005, 127, 11436-11441.

(63) Braun, C. S.; Vetro, J. A.; Tomalia, D. A.; Koe, G. S.; Koe, J. G. Middaugh, C. R. J. Pharm. Sci. 2005, 94, 423-436.

(64) NIH Image VDM, version 1.58 VDM; National Institutes of Health: Bethesda, MD.

(65) Horkay, F.; Tasaki, I.; Basser, P. J. Biomacromolecules 2000, 1, 84-90.

(66) Takano, M.; Ogata, K.; Kawauchi, S.; Satoh, M.; Komiyama, J. Polym. Gels Networks 1998, 6, 217-221.

(67) Liu, X.; Tong, Z.; Hu, O. Macromolecules 1995, 28, 3813-3817.

(68) Firestone, B. A.; Siegel, R. A. J. Biomater. Sci. Polymer ed. 1994, $5,433-438$.

(69) Livolant, F.; Leforestier, A. Prog. Polym. Sci. 1996, 21, 11151164.

(70) Zinchenko, A. A.; Yoshikawa, K. Biophys. J. 2005, 88, 41184123.

(71) Tamura, T.; Yoshida, S.; Miyamoto, Y.; Kawauchi, S.; Satoh, M.; Komiyama, J. Polym. Int. 2000, 49, 147-151.

(72) Ma, Ch.; Bloomfield, V. Biophys. J. 1994, 67, 1678-1681.

(73) Zinchenko, A. A.; Sergeyev, V. G.; Yamabe, K.; Murata, S. Yoshikawa, K. Chembiochemistry 2004, 5, 360-368.

(74) Hackl, E. V.; Kornilova, S. V.; Blagoi, Y. P. Int. J. Biol. Macromol. 2005, 35, 175-191.

(75) Costa, D.; Burrows, H. D.; Miguel, M. Langmuir 2005, 21, 1049210496

(76) Tajmir-Riah, H. A.; Ahmad, R.; Naoui, M. J. Biomol. Struct. Dyn $1993,10,865-877$.

(77) Lee, J. Y.; Nam, S. H.; Im, S. Y.; Park, Y. J.; Lee, Y. M.; Seol, Y. J.; Chung, C. P.; Lee, S. J. J. Controlled Release 2002, 78, 187-197.

(78) Stake, I.; Takahashi, T.; Hayakawa, K.; Maeda, T.; Aoyagi, M. Bull. Chem. Soc. Jpn. 1990, 63, 926-928.

(79) Hansson, P.; Almgren, M. J. Phys. Chem. 1995, 99, 9201-9209.

(80) Khokhlov, A. R.; Kramarenko, E. Yu. Macromolecules 1996, 29, $681-685$

(81) Schneider, S.; Linse, P. Macromolecules 2004, 37, 3850-3856.

(82) Costa, D.; Hansson, P.; Schneider, S.; Miguel, M.; Lindman, B. Biomacromolecules 2006, 7, 1090-1095.

(83) Rosén, O.; Sjöström, J.; Piculell, L. Langmuir 1998, 14, 57955799.

(84) Isogai, N.; Narita, T.; Chen, L.; Hirata, M.; Gong, J. P.; Osada, Y Colloids Surf., A 1999, 147, 189-201.

(85) Dias, R.; Lindman, B.; Miguel, M. J. Phys. Chem. B 2002, 106 , $12608-12612$.

(86) Bae, Y. H.; Okano, T.; Kim, S. W. Pharm. Res. 1991, 8, 531537.

(87) Karapetian, A. et al. J. Biomolec. Struct. Dyn. 1996, 14, 275-283.

(88) Rittich, B.; Španová, A.; Falk, M.; Beneš, M. J.; Hrubý, M. J. Chromatogr., B 2004, 800, 169-173. 